\title{
LA ETAPA FORMATIVA (1940-1951): DEBATES ESTÉTICOS EN LA LÍRICA TEMPRANA DE HÉCTOR ROJAS HeRAZO*
}

\author{
The Formative Stage (i 940-I95 I): \\ Aesthetic Debates in the Early Poetry \\ of HÉctor Rojas Herazo
}

Emiro Santos García ${ }^{1}$

* Artículo derivado de la tesis doctoral Estudio
previo y edición crítica de la obra poética de Héctor
Rojas Herazo (1940-2006), desarrollada en el
Doctorado en Literatura de la Universidad de
Antioquia, Colombia.

Cómo citar este artículo: Santos García, E. (2021). La etapa formativa (1940-1951): debates estéticos en la lírica temprana de Héctor Rojas Herazo. Estudios de Literatura Colombiana 49, pp. 37-52. DOI: https://doi. org/10.17533/udea.elc.n49a02

1 https://orcid.org/0000-0003-0545-0150

emirosantosgarcia@gmail.com

Universidad de Cartagena, Colombia
Editores: Andrés Vergara Aguirre, Christian Benavides Martínez

Recibido: 15.02 .2021

Aprobado: 21.05.2021

Publicado: 30.06 .2021

Copyright: (2021 Estudios de Literatura Colombiana. Este es un artículo de acceso abierto distribuido bajo los términos de la Licencia Creative Commons AtribuciónNo comercial - Compartir igual 4.0 Internacional
Resumen: La poética de Rojas Herazo hace parte de un panorama histórico, político y cultural definido por el surgimiento y la difícil consolidación de los procesos modernizadores de la sociedad colombiana, y por la crisis y disolución de la tradición conservadora. Se trata de una historia poética cuya etapa formativa abarca los años de 1940 y 1951, y antecede la publicación de sus seis poemarios. A partir del rastreo de los primeros poemas publicados en la prensa regional y capitalina, que no han sido reunidos en compilaciones posteriores, así como de su recepción crítica, revisaremos las condiciones de emergencia de la lírica temprana del autor en el marco de los debates piedracielistas y americanistas de la década del 40 .

Palabras clave: Héctor Rojas Herazo; poesía colombiana; paisaje; piedracielismo; americanismo.

Abstract: The poetic of Rojas Herazo is part of a historical, political, and cultural landscape defined by the emergence and difficult consolidation of Colombian society's modernizing processes, as well as the crisis and dissolution of the conservative tradition. It is a poetic trajectory whose formative stage covers the years 1940 and 1951 before the publication of Herzo's poetry books. After tracking his first poems published in the regional and capital press, in addition to their critical assessment, we will review the conditions of emergence and reception of the author's poetry, framed in the "piedracielistas" and "americanistas" debate in the 1940'.

Keywords: Héctor Rojas Herazo; Colombian poetry; landscape; piedracielismo; Americanism. 


\section{La "pre-historia" lírica: visiones arcádicas del paisaje}

En 1940, cuando Héctor Rojas Herazo publica sus primeros poemas, ${ }^{1}$ Colombia padece las consecuencias del colapso del segundo periodo de la República Liberal y el recrudecimiento del enfrentamiento entre liberales y conservadores, que conducirá ocho años más tarde al asesinato del caudillo liberal Jorge Eliécer Gaitán y al periodo conocido como "La Violencia". Si bien el proyecto de "La Revolución en Marcha", impulsado por el presidente liberal Alfonso López Pumarejo, promovió un Estado laico, intervencionista, capaz de oponerse al estado clerical decimonónico, no constituyó una ruptura definitiva con los modelos culturales de la Hegemonía Conservadora (Urrego Ardila, 2002), ni con la concepción ancilar del intelectual de la tradición clásica. Pero el reconocimiento de la protesta popular y el fomento de las agrupaciones sindicales como agentes de cambio, la ampliación del sistema educativo y la preocupación por el acceso a la cultura, que representaron las Bibliotecas Aldeanas y la creación de la Radiodifusora Nacional de Colombia, por ejemplo, redefinieron las lógicas de representación de las producciones locales en el ámbito nacional.

Poetas y narradores entre los que se destacan Luis Carlos López, José Félix Fuenmayor, Jorge Artel, Héctor Rojas Herazo, Gabriel García Márquez y Álvaro Cepeda Samudio, y artistas plásticos como Alejandro Obregón, Enrique Grau y Cecilia Porras contribuirían a proyectos artísticos que se apartan del programa regeneracionista que había desplazado las manifestaciones populares más allá de la "Atenas Suramericana". Nacido en 1920, en Santiago de Tolú, pequeño pueblo del entonces departamento del Bolívar Grande, Rojas Herazo inicia su formación estética como admirador de la escuela piedracielista, grupo generacional de influencia hispánica que se opuso a la estética del parnasianismo centenarista, y que tendría en Cartagena su interpelación local en el movimiento Mar y Cielo. ${ }^{2}$ El debate piedracielista, que se centró en la figura canónica de Guillermo Valencia, favoreció, a pesar de sus múltiples caracteres reaccionarios - la continuidad de un ideal espiritualista y sublimado de las formasEntre su prolífica obra destacan los poemarios Rostro en la soledad (1952), Tránsito de Caín (1953), Desde la luz preguntan por nosotros (1956), Agresión de las formas contra el ángel (1961), Las ülceras de Adán (1995) y Candiles en la niebla (2006). En 1999 recibió el Premio Nacional de Poesía José Asunción Silva.

Los grupos locales “Mar y Cielo", en Cartagena, y "Arena y Cielo”, en Barranquilla, son buena muestra de la receptividad que Piedra y Cielo tuvo en el Caribe. Para una crónica de los días de Mar y Cielo, en palabras de algunos de sus integrantes, véase "Gustavo Ibarra Merlano. Un humanista frente al mar" de Tatis Guerra (2007), y el artículo "El grupo de Cartagena”, de José Nieto, publicado el 25 de julio de 1995 en El Tiempo. 
la toma de posición sobre la autonomía del lenguaje poético. Para 1940, Rojas Herazo tiene veinte años y cultiva un lenguaje que deja entrever las lecturas de los poetas del Siglo de Oro español y del romancero de la Generación del 27, la apología de modernistas tardíos como Eduardo Castillo y Porfirio Barba Jacob, y de los piedracielistas Jorge Rojas y Eduardo Carranza.

Durante la etapa formativa, la circulación en prensa de su trabajo lírico y crítico será fundamental. Rojas Herazo publica en 1940 seis poemas en el diario liberal El Heraldo de Barranquilla, que llevan por título "Acróstico" (17 de mayo), "Canción de la niña imposeída" (9 de julio), "Romance de aquella noche de alfileres blancos" ( 9 de agosto), "Exégesis breve del ave empapada de horror" (3 de septiembre), "El jaspe del sueño dorado en Ku-Tai" (12 de septiembre) y "Virilidad del yunque” (17 de diciembre); y el poema "Fuegos propiciatorios" (agosto), en la revista conservadora América española. Tanto las resonancias grecolatinas de un poema como "Acróstico", que recurre a los juegos del culteranismo y conceptismo barroco; y las fascinaciones orientalistas de "Jaspe del sueño dorado en Ku-tai", que debe lo mismo al modernismo parnasiano que a las geografías indonesias de Emilio Salgari; o la idealización de la "amada" de "Canción de la niña imposeída", que debe tanto a Piedra y Cielo, definen un ideal de belleza sublimado y de pretensiones ahistóricas. En "Canción de la niña imposeída" leemos:

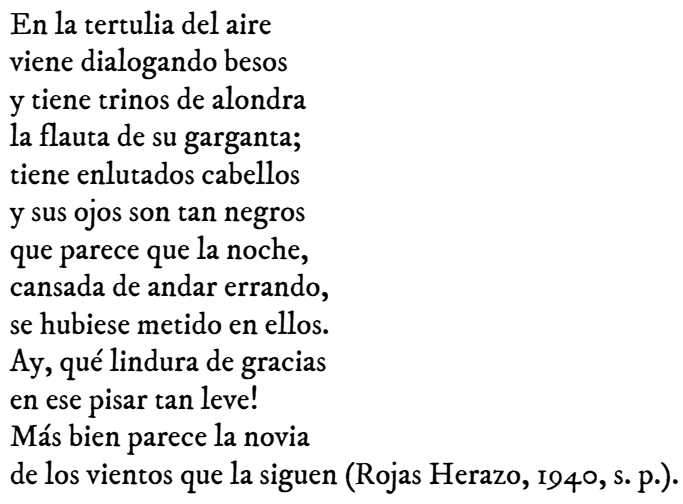

En lo que respecta a "Fuegos propiciatorios", el muy breve comentario atribuible a Gabriel Porras Troconis, que acompaña el poema, sostiene: "acogemos hoy con positiva satisfacción estos versos del joven poeta Rojas Herazo, quien por sus señaladas condiciones mentales y su atemperado buen gusto dentro de las nuevas corrientes literarias, 
es una verdadera promesa para las letras patrias" (América española, 1940, p. 288. Las cursivas son nuestras). El "atemperado buen gusto" que refiere Porras Troconis -intelectual conservador en el que encarna la aspiración cultural caribeña de "raza” y "pureza” hispánicas - corresponde a una concepción idealista de la función poética, que colinda con las ambiciones religiosas de Miguel Antonio Caro, Antonio Gómez Restrepo, Luis María Mora y Rafael Maya. Los primeros poemas de Rojas Herazo abundan en una desterritorialización del paisaje y del cuerpo femenino, que invoca naturalezas eglógicas y exóticas. $\mathrm{O}$ lo que es lo mismo, sus poemas comparten el desinterés de los intelectuales y poetas nacionales por los grandes conflictos que socavaban las representaciones del campo colombiano como locus amoenus y del campesinado como clase complaciente.

La visión arcádica de esta concepción juvenil de arte permea no solo sus poemas, sino su crítica literaria, tal cual se hace evidente en la valoración de la obra del poeta sucreño Adolfo Martá, quien en una composición como "Romance de la niña campesina”, publicada el 3 de junio de 1940 en El Fígaro de Cartagena, idealiza la violación de una joven campesina bajo las convenciones patriarcales del romancero español. Rojas Herazo (2003a) elogia a Adolfo Martá con un lenguaje vegetal de raigambre piedracielista; como a un poeta con quien no es

[...] raro que mientras leamos un romance [...], el cuarto que antes era inoloro se llene de pronto de un suave aroma de mirtos con que una muchacha campesina ha adornado el luto de sus cabellos o que sintamos el campanilleo de las espuelas, o el retozo de un alazán soberbio con músculos de ventisca portando en sus lomos nerviosos al capataz Calasán (p. 93).

Así, los campesinos costeños habrían encontrado en Martá "su más gallardo y autorizado vocero y a la vez su apóstol-poeta” (p. 93).

E1 24 de agosto del mismo año, el intelectual socialista Antonio García Nossa publica en El Tiempo el artículo titulado "De Valencia a Carranza”, un revelador compendio sobre las dificultades de la poesía colombiana del momento. Para García Nossa (1940), la falta de entendimiento de la realidad americana, que había recurrido a los mitos griegos, con Guillermo Valencia, o al indigenismo y criollismo, con José Santos Chocano, evidencia un vínculo colonial en la representación del paisaje y de los conflictos humanos. Las generaciones poéticas recientes no serían ajenas a ello y apenas dispondrían de un conocimiento "vago" y "libresco", que, como mecanismo de interpretación de lo real, apelaba al neorromanticismo de Bécquer, Jiménez, Salinas y Alberti. "Lo grave del fenómeno está en que ha 
cambiado la época y nuestra poesía permanece sin cambios substanciales [...], sin recoger ninguna de las grandes angustias o pasiones que pesan en la sensibilidad colombiana” (p. 2). Para García Nossa, este alto grado de insensibilidad nacional expresaba un estado patológico, un "sentido feudal del amor", un "erotismo propio de insatisfechos sexuales” (p. 2).

El progresivo acceso de Rojas Herazo a nuevas lecturas de poetas y narradores continentales le ayudará al cuestionamiento de la concepción de una poesía desinteresada de los rigores de la historia. Gabriel García Márquez (2005), compañero de trabajo durante el fin de la etapa formativa, concluye, en una nota de El Heraldo del 3 de abril de 1950, que

[...] pasada la tempestad metafórica, olvidado el fogonazo del último relámpago, tal vez sea doloroso reconocer que fue muy poco - casi nada en realidad - lo que nos dio Piedra y Cielo, aparte de cierto romanticismo audaz para romper los códigos estéticos vigentes antes de ese movimiento, aunque para caer bajo la dictadura de otro (p. 212).

Si bien es cierto que Rojas Herazo irá más allá del agotamiento del lirismo piedracielista y lo desmontará, nunca dejará de considerar este movimiento como el inicio de una revolución nacional anticipada por poetas caribeños como Néstor Augusto Malo y Óscar Delgado (Rojas Herazo, 2003a, pp. 100-101).

\section{La respuesta americana: el problema del hombre de "nuestro tiempo"}

En 1947, en El Heraldo de Barranquilla, Héctor Rojas Herazo publica varios poe-

mas que ilustran el derrumbamiento de las influencias de Piedra y Cielo. El poeta se encamina a un lenguaje elegiaco y a una imaginería religiosa secular que explora la autoconciencia corporal, la otredad y la penuria del lenguaje como mecanismos de interpretación del "silencio de Dios". Inicia así el redimensionamiento de la función social de la poesía bajo las implicaciones éticas de posguerra — dos años antes ha finalizado la Segunda Guerra Mundial, en una "Europa que se nutre de sus propias ruinas para salvar — en la tremenda balanza de la posguerra- el equilibro del mundo" (Rojas Herazo, 2003a, p. 102)—; gravita la amenaza del exterminio nuclear y recrudecen los horrores de la violencia en Colombia. No deja de ser revelador el hecho de que el joven poeta acuda a la figura bíblica de Job, el fatídico inocente que, ante las preguntas por el sentido del dolor humano, no recibe más respuesta que el absoluto enigma de la voluntad divina: 


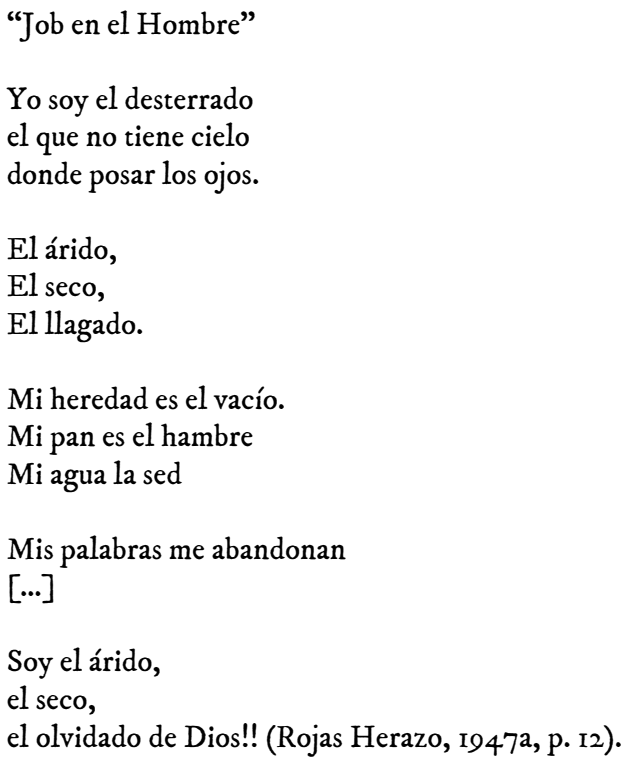

Tampoco resulta extraño que un poema como "Palabra rescatada" - mutilado en el único ejemplar conservado en el Archivo de El Heraldo- persiga una "palabra verdadera", una "palabra liberada", con la que sea posible recuperar la certeza de lo humano. Hemos llegado a una extinción del paisaje bucólico y a un llamado a la colectividad que ignora la muerte del "otro", en este caso del soldado campesino que abona con su sangre-savia y su fusil-arado el campo sobre el que caminan los hombres:

"Palabras elegiacas a un soldado"

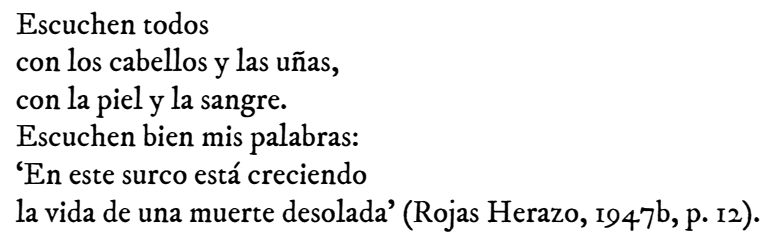

Si bien es cierto que los poemas del 47 no enuncian referencias directas a la violencia nacional, como sí ocurrirá con "Los desplazados” y "Lamentación del campesino emasculado", fechados en 1960, pero publicados en su libro póstumo - Candiles en la niebla, 2006-, existe una relación constitutiva entre la tierra y el hombre, entre la naturaleza y la muerte, que evoca los poemas de Walt Whitman y Edgar Lee Masters sobre la Guerra Civil estadounidense, pero reactualizados bajo la memoria de 
las guerras civiles colombianas de finales del XIX y de la primera mitad del xx (una memoria que el poeta debe a los relatos de su tío Eneas y a las notas de prensa sobre los veteranos de la Guerra de los Mil Días, que publica a finales de los 40).

Acerca de estos nuevos poemas, el escritor catalán Ramón Vinyes y el periodista barranquillero Alfonso Fuenmayor, miembros del Grupo de Barranquilla, publican dos entusiastas comentarios en una página completa dedicada al poeta. Ramón Vinyes (1947), en "El hombre y su voz", afirma que, con un "discreto sentido de la dignidad interior", Rojas Herazo cumple una misión que ha "superado ya muchas etapas y que hoy se traduce en estos poemas". Así mismo, lo saluda como un "auténtico poeta que ha logrado la difícil realización de auténtica poesía", como un autor de composiciones de "hondura vital extraordinaria” y de "tranquila y poderosa respiración” (p. 12). Por su parte, Alfonso Fuenmayor (1947) sostiene:

[...] ahora después de muchos viajes alrededor de sí mismo más largos y más penosos que los otros, Rojas Herazo se ha acercado peligrosa y gozosamente a su propia identidad lírica, a su sincera y personal expresión, a su nota verdadera [...]. Y [...] obedeciendo a un noble evangelio de lealtad para con el hombre y para con la naturaleza, Rojas Herazo, sin vacilación, como una campana embriagada, traza su limpio ademán, dibuja su gesto puro y dice con mesiánico acento de profeta mayor, unidad, integración, clama paz y con su voz firme y fraternal vocifera simpatía, mientras un hálito de heroísmo lo conmueve (p. I2).

Para Alfonso Fuenmayor, Rojas Herazo pertenece a una nueva juventud que no se escuda ya en los artificios retóricos, en el "caprichoso y monótono disfraz que sigue otorgándole, entre necios aplausos, un tenaz lirismo internacional” (p. 12), y que quiere ser entendida. Una consideración que establece vínculos con los debates estéticos de los 40, que conducen a la emergencia de los "post-últimos" o "cuadernícolas", rótulos que reunieron a creadores tan heterogéneos como Jaime Ibáñez, Fernando Charry Lara, Andrés Holguín, Álvaro Mutis, Jorge Gaitán Durán, Rogelio Echavarría y Eduardo Cote Lamus. Antes de ser homogeneizados bajo el rótulo centralista de "Generación de Mito", los "post-piedracielistas" convinieron en reconocer la importancia histórica de Piedra y Cielo — sus aportes a una ruptura con el lenguaje del tardío modernismo parnasiano y centenarista-, pero no acogieron el carácter sublimado de su concepción de poesía. En un artículo publicado en la revista liberal Sábado, el poeta Álvaro Sanclemente (1948) asegura sobre uno de los libros de Jorge Gaitán Durán: 
[...] es una demostración palpable de que hasta su sensibilidad ha penetrado una gran fuerza, demoledora y creadora a un mismo tiempo, que no es otra cosa que esa infinita angustia del hombre de nuestra época que no tiene tiempo para la contemplación inmóvil de los efectos producidos por las palabras, porque la urgencia imperativa de vivir, de escapar del cerco implacable de acechanzas de todo orden que lo rodean, lo obligan a mirar hacia el fondo de su torturado corazón (p. 5$)$.

Podemos decir que la madurez estética de Rojas Herazo inicia en la segunda mitad de los 40, con la revisión crítica de tres tradiciones continentales exploradas durante su etapa cartagenera: 1) la lírica de los poetas colombianos Luis Carlos López, Porfirio Barba Jacob, León de Greiff y Aurelio Arturo, quienes cuestionan, continúan o superan las figuraciones modernistas; 2) la poesía civil de los norteamericanos Walt Whitman, Edgar Lee Master, Robert Frost, Stephen Vincent Benét y Archibald MacLeish, quienes, "más allá del empuje y vastedad de sus cantos, más allá del impulso universal que arquitectura sus mensajes [...] están aferrados a su paisaje, a sus costumbres y a sus hechos, con inexorable dignidad agraria" (Rojas Herazo, 2003a, p. 115); y 3) las ambiciones panhumanistas del poeta peruano César Vallejo y del poeta chileno Pablo Neruda. Y aunque en un primer momento encontraremos una irrestricta admiración por la obra de Barba Jacob (p. 98), Rojas Herazo acabará por sostener el 27 de mayo de 1951 que el acento del antioqueño quedaba atrapado en los "áureos grilletes del modernismo" (p. 133).

E1 reconocimiento de las limitaciones y posibilidades de la herencia modernista, la necesidad de hermandad con el hombre de posguerra y la importancia de un ideal colectivo (donde se escuchan voces del muralismo mexicano como procedimiento de rebeldía social y de exploración originaria), demandan para Rojas Herazo una reformulación de los deberes del poeta moderno americano. Exalta el autor la concepción arriesgada de la poesía de Luis Carlos López, ya que sus mecanismos de contravención y distorsión poética son fieles a su momento; encuentra en la celebración de la vida y de lo cotidiano, en la dignificación de lo trivial y en la fraternidad de Lee Masters, la línea de salvación que debe continuar la poesía americana (Rojas Herazo, 2003a, pp. 115-116); y admira el ascetismo lingüístico, el dolor humano y el mesianismo de César Vallejo, "poeta indolatino [que] se somete a sufrir y a transmitir, en patéticas letanías, el suplicio de su tiempo, de su lenguaje y de su raza” (p.133). 
La enunciación de las necesidades americanistas puede rastrearse hasta su periodo de colaboración en El Universal de Cartagena. ${ }^{3}$ Un proyecto ideológico construido en connivencia con Gabriel García Márquez y Gustavo Ibarra Merlano, bajo el consentimiento del periodista y jefe de redacción Clemente Manuel Zabala. Tras un viaje a Santiago de Tolú, que engendra diversas columnas sobre el mundo rural y la infancia, y a la sombra de la censura posterior a los disturbios motivados por el magnicidio de Jorge Eliécer Gaitán el 9 de abril de 1948, y del asesinato del caudillo liberal Braulio Henao Blanco el 23 de junio del mismo año en Cartagena, Rojas Herazo propone la invención de un poeta que compendie las búsquedas estéticas más urgentes de su generación: la autonomía intelectual del pensamiento americano, la puesta a tiempo con la modernidad literaria, el compromiso ético de América en el nuevo concierto histórico, la construcción de un nuevo ideal de hombre que determine el futuro de la humanidad y la relevancia del discurso poético en la construcción de ese mundo (Rojas Herazo, 2003a, p. 109).

Tal programa se encuentra soportado por cuatro notas de prensa, dos entrevistas y dos poemas atribuibles a Rojas Herazo, ${ }^{4}$ que delinean una lectura crítica y renovadora de la literatura continental, y que van acompañados de una revaloración de la hispanidad como "meridiano inexorable del pensamiento occidental" (p. 102). Una ambición integradora que debe mucho a la filosofía cósmica de José de Vasconcelos y al proyecto civilizatorio que el mexicano considera favorecido por las condiciones territoriales, raciales y espirituales de las antiguas colonias hispánicas y lusitanas, destinadas a una nueva forma de humanidad o "quinta raza". El 27 de junio de 1948 aparece la primera nota sobre el poeta y novelista imaginario César Guerra Valdés, nicaragüense de paso por Cartagena, en camino a Venezuela, donde expondrá una serie de conferencias sobre las relaciones culturales entre los países hermanos y sobre el "porvenir de nuestro hemisferio":

3 En 1946, Rojas Herazo adelanta un primer acercamiento a las preocupaciones continentalistas suramericanas y centroamericanas con la entrevista al pensador y político peruano Víctor Raúl Haya de la Torre, fundador de la Alianza Popular Revolucionaria Americana (APRA) y uno de "los más grandes revolucionarios de América" (Rojas Herazo, 2003a, p. 19).

$4 \quad$ La nota "Un poeta nicaragüense" fue publicada el 27 de junio de 1948; "Guerra Valdés, crítico y polemista”, el 29 de junio; una semblanza de "Punto y aparte”, el 29 de junio; “En el año de 1940”, el 1 de julio de 1948. Las entrevistas "El Hombre de América debe saber cual [sic] destino merece y cual [sic] desea para sacar en conclucion [sic] cual [sic] necesita" y "Un diálogo con Guerra Valdés: 'Dante nos coloca su doncella en el cielo y Carranza la deja en la ventana' dice el maestro" fueron publicadas, respectivamente, el 30 de junio y el 1 de julio - esta última ha desparecido del ejemplar conservado en el Archivo de El Universal, digitalizado por el Banco de la República-. Los poemas "Invocación vital para mi hermano el hombre" e "Invitación al hombre universal", por su parte, en la sección "Antología”, el 2 de julio. 
[...] lo verdaderamente admirable, en la parábola estética de Guerra Valdés, es la capacidad de que ha hecho gala para cocechar [sic], con igual profundidad y fortuna, en los dos estadios en que, forzosamente, se encuentra dividida la vieja y la nueva literatura. Nacido en 1890 arriba, al comienzo de nuestro siglo, cargado con el áureo fardo del modernismo, en ese entonces capitaneado por Rubén [Darío]. Fue un gran poeta finisecular. Y, al mismo tiempo, quien primero dio, en su patria, la clarinada de la vanguardia. Pablo Neruda, comentando su libro de poemas, 'Un jinete y el infinito', sobre el cual se dio en América la batalla campal de aquella escuela, dijo lo siguiente: "Es un libro orgánico nutrido de hemoglobinas líricas. Es la voz de un hombre de América cantando con la sal, el yodo y el vegetal, de sus mares, de sus selvas y de sus minerales" (Rojas Herazo, I948a, p. 4. Las cursivas son nuestras).

Esta nota recoge los principales axiomas del periodismo de Rojas Herazo enunciados como parábola: la unidad cultural de América, la comprensión prospectiva del hemisferio, los alcances y las limitaciones del modernismo, que establece un antes y un después en los modos de producción literaria, la importancia de una red intelectual y lírica que otorgue consistencia a sus propuestas y la necesidad de un nuevo hombre, cuya enunciación desemboca años más tarde en una concepción sintética de lo humano y de la cultura americana como fundamento de una mitografía personal de redención terrestre. Debe tenerse en cuenta, sin embargo, que los debates ideológicos sobre la integración continental, detonados a finales del xIX por el intervencionismo norteamericano en el Caribe y Centroamérica, la Revolución mexicana y la Revolución rusa, el hispanismo metropolitano y los latinoamericanismos de corte indigenista e hispanista (Ortemberg, 2017, p. 101), ubican las propuestas de Rojas Herazo en un campo de tensión entre los intereses políticos y económicos norteamericanos, traducidos en la "defensa" panamericana de la autonomía continental frente a los viejos colonialismos europeos, y las búsquedas nacionalistas democráticas y las simpatías socialistas movilizadas en Colombia por políticos como Jorge Eliécer Gaitán. Al respecto, escribe Rojas Herazo el 12 de mayo de 1948:

El mundo tiene hoy, en cualquiera de los órdenes de la cultura, una sola preocupación: definir el cariz ideológico de la especie. [...] Vivimos el siglo de las sintesis colosales. De allí que Estados Unidos y Rusia se hayan convertido, como experiencias políticas, en los dos grandes símbolos de nuestro tiempo (Rojas Herazo, 2003b, p. 332).

La programática americanista de Rojas Herazo asume dos líneas. Por un lado, una teleología de origen mediterráneo en torno a la finalidad de la "raza" humana. Por otro, la visión sintética de la cultura hispánica como transmisora de los saberes del mundo. Como cabe esperar, el ámbito más desarrollado es el estético que, en una entrevista a Guerra Valdés —escrita a tres manos por Rojas Herazo, García Márquez 
y Gustavo Ibarra Merlano (Arango, 1995, pp. 74-75)—, cuestiona la lírica y la narrativa americana contemporáneas, ya que se centran en el paisaje y no en el ambiente. La entrevista ataca, igualmente, la miopía de la poesía previa al piedracielismo, con Rafael Maya, un "hombre que piensa en griego, se martiriza en español y escribe en payanés"; las búsquedas del piedracielismo, que ha "puesto su bazar de muchachas, de días y de nubes, precisamente en el umbral del territorio, delirante y masculino, del llano colombiano"; y el intelectualismo burgués de poetas recientes como Jaime Ibáñez y Jorge Gaitán Durán, quienes parecen proclamar a la hora de publicar: "sepan ustedes, lectores de Colombia, que nosotros sabemos escribir. Y lo hacemos en todas las formas y maneras" (Rojas Herazo, 1948b, p. 8).

De esta experiencia americanista nacerán dos poemas que, debido a su lenguaje fraterno y a su imaginería de corte religioso —en la misma línea de los poemas publicados un año antes en El Heraldo- son atribuibles a Rojas Herazo. Estos son: "Invocación vital para mi hermano el hombre" e "Invitación al hombre universal". Dos composiciones cuya modalidad enunciativa apela a la exhortación panhumanista y prefiguran no solo el tono, sino la sintaxis y las imágenes edénicas de poemas como "Adán”, "Narciso incorruptible" y "El encuentro", que encontramos en su primer poemario, Rostro en la soledad (1952). En "Invocación vital para mi hermano el hombre", vemos un llamado a la otredad, que busca paliar el abandono cósmico:

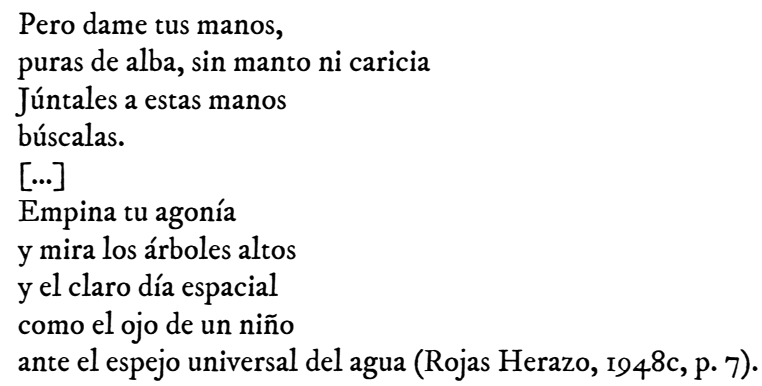

En cuanto al segundo poema, advertimos una cartografía simbólica tributaria del Neruda de Canto general, 5 que convoca la voz de los negros de Lousiana, el jipido de los gauchos de la pampa, la sensorialidad de las Antillas y de los Andes, y desemboca en el gran gesto de América abierto a Europa, Asia y África:

$5 \quad$ Más adelante, Neruda será revisado, porque se "le trueca en anatema político lo que podría ser un dramático documento del destrozo y desesperanza de nuestro tiempo" (Rojas Herazo, 2003a, p. 133). 
Mira este gesto de dar que tiene América.

Mira sus claras maderas sus ríos al mar, sus largos senderos, cargados de bestias y de frutos.

Todo esto es América.

Y todo esto soy yo mismo.

Cualquier montaña me sirve de ventana

para llamar a los hombres

y señalar a las estrellas

por la luz de sus nombres (Rojas Herazo, 1948d, p. 7).

La importancia de "Invocación vital para mi hermano el hombre" e "Invitación al hombre universal" radica en que son los primeros poemas en cristalizar las preocupaciones de poemarios como Rostro en la soledad (1952), Tránsito de Cain (1953) y Desde la luz preguntan por nosotros (1956). Un compendio de inquietudes ideológicas y simbólicas que soportan la mitologización americana como un paliativo al desamparo del hombre de posguerra. La concepción de "mito" e "historia" que desprende la postura americanista de Rojas Herazo permitirá la construcción de una bistoria mítica o relato de la caída y redención humanas en su producción poética futura.

\section{El fin de la etapa formativa: antes de Rostro en la soledad}

Después de la aventura americanista de César Guerra Valdés, el 18 de septiembre de 1948, en una nota atribuible a Clemente Manuel Zabala, leemos un balance sobre la poesía de Rojas Herazo: la exaltación de un joven que ha abierto una renovación estética y una sensorialidad y metafísica nuevas para Colombia. Esta nota resulta importante no solo por su carácter sintético, sino porque anuncia el título del que hasta ese momento sería su primer poemario, Lámparas en la niebla —un título que será recuperado por el autor para su último proyecto lírico, que aparecerá de manera póstuma intitulada Candiles en la niebla-.

Su obra, dispersa en varias ciudades del país, es una de las más sinceras constancias de la reciente lírica colombiana. Todos sus críticos apuntan a su fuerza. Quisiéramos, más bien, destacar su manera de doblegarla al misterio. Su ademán de potencia que implora una gracia. Su plástica de ávido torso en busca de ojos propios donde situar la respiración [...]. Atenta siempre al mundo como signo de una Voluntad Superior, [su poesía] busca aquel idioma perdido para nosotros y restaurado milagrosamente en una simple rosa olvidada de todos los seres (Zabala, 1948, p. 7). 
A partir de este momento, encontraremos diversas referencias sobre la gestación de un primer poemario. Una posibilidad editorial que vuelve a anunciarse en el apartado que acompaña la publicación de "Jaculatoria a los seres creados", en Revista de América (octubre-noviembre de 1948), esta vez bajo el nombre de Arribo terrestre; y en la nota titulada "Un saludo a Rojas Herazo" (El Universal, 7 de febrero de 1950). En el caso de "Jaculatoria de los seres creados", el poema retoma las convenciones oratorias cristianas, aunque volcadas hacia la inmanencia terrestre: el árbol, el río,la rosa y el hombre como integrantes de la continuidad cósmica. Pero si la inclusión de "Jaculatoria..." en un medio de tan amplia difusión como Revista de América resulta significativa, son los poemas publicados el 1 de octubre de 1949 en la revista Sábado los que marcan la inflexión definitiva de la etapa de formación. Estos llevan por título: "Mujer en la luz", "El ángel visitante", "Poema de la profunda despedida", "Palabras elegíacas a un soldado", “Tiempo de la agonía” "El habitante destruido" - tres de ellos habían aparecido en 1947, en El Heraldo, y uno en 1948, en El Universal - Acerca de su publicación, leemos el 1 de octubre en El Universal:

Para quienes estamos tan estrechamente vinculados a su hombre [...], tan repartidos en los vitales espacios de su obra, esta selección de poemas que publica la gran revista capitalina tiene mucho de encuentro, si no completamente con nosotros mismos, por lo menos con muchos de nuestros instantes más amados (El Universal, 1949, p. 4).

De un poema como "El ángel visitante", podemos decir que incorpora los temas domésticos de la casa, la mesa familiar y la presencia angélica, que encontraremos más tarde en "La casa entre los robles"; pero es "El habitante destruido" el poema que abre y consolida el lenguaje simbólico de carácter mitologizador de su futuro primer poemario:

Todo en verdad fue construido por el tiempo.

El quiso ser ladrillo y bronce

Y sopló en nuestras manos

para que aprisionáramos el aire y el perfume

en el recinto de los edificios.

Entonces todos trabajaban como construyendo

algo que iba a ser tranquilo y perdurable.

Y recibían su jornal de júbilo

con cada espacio habitable robado a la soledad.

$[\cdots]$

Palabras, palabras en el polvo,

mi voz también ruina y espacio marchitable (Rojas Herazo, 1949, p. ๑).

El 7 de febrero de 1950, cuatro meses más tarde, El Universal destaca el vitalismo de los poemas aparecidos en la prensa bogotana: "Por sobre la producción afectada del más ma- 
nido retoricismo a que nos tiene acostumbrados la nueva promoción poética, los últimos versos de Rojas Herazo son indudablemente la experiencia más seria que se haya hecho en nuestro mundo literario para revaluar tan nobilísima actividad intelectual" (E1 Universal, 1950, p. 4). "El encuentro" y "El habitante destruido" son poemas construidos con lo que el comentador define como la opulencia y eternidad de un auténtico maestro, lo que podrá comprobarse cuando “aparezca su próximo libro 'Arribo terrestre' [...] que será su consagración como una de las más resonantes voces de poeta con que va a enriquecerse la poesía colombiana”(p. 4). El 14 de marzo, un mes después, García Márquez (2005) se refiere a "El habitante destruido" como una de "las obras fundamentales de nuestras letras":

La suya es una poesía elemental, cuyo sometimiento a la forma del canto es posible apenas por la fuerza con que el poeta se enfrenta a sus apremios interiores, por la destreza con que maneja sus instrumentos esenciales. Poesía desbordada, en bruto, la de Rojas Herazo no se daba entre nosotros desde que las generaciones literarias inauguraron el lirismo de cintas rosas y pretendieron imponerlo como código de estética. Rojas Herazo la rescató del subsuelo, la liberó de esa falsa atmósfera de evasión que la venía asfixiando y en donde el hombre parecía haber reemplazado sus hormonas por refinados jugos vegetales y se enfrentaba a una muerte inofensiva y complaciente. Rojas Herazo volvió a descubrir el hombre (p. 184).

Si bien con la página de Sábado culmina el periplo formativo de Cartagena y Barranquilla, e inicia el de Bogotá, la valoración de García Márquez de febrero de 1950 se dirige no tanto a los poemas aparecidos en la capital como a los que, en un círculo cerrado, han conocido los amigos, y que pide compartir en Barranquilla, ciudad donde habría un ambiente más propicio que Cartagena para un "acento nuevo" que está en la línea poética de José Asunción Silva, Porfirio Barba Jacob y León de Greiff. Es decir, en la "línea del hombre”. En 1951, Héctor Rojas Herazo se establece en Bogotá. El 24 de octubre del mismo año, en una columna publicada en Cartagena, leemos: "Allí [en Bogotá] tendrá, sin duda, mejores oportunidades de demostrar su extraordinario valor y de imponerse definitivamente como lo que es en realidad desde hace muchos días: el más alto poeta en este momento en Colombia, hombro a hombro con los grandes de América" (E1 Universal, 1951, s. p.).

\section{Conclusiones}

El periodo formativo de Rojas Herazo comprende tres fases que giran en torno al problema del nombramiento de la geosimbólica y el "hombre". La primera fase está caracterizada por una reapropiación literaria que entrecruza la poesía áurea española, el modernismo hispanoamericano y el piedracielismo nacional (con sus respectivas 
deudas a la Generación del 27), y tiene como propósito ahondar en las posibilidades poéticas validadas por la tradición hispanista. La enunciación lírica que procede de esta le permite una reflexión sobre la plasticidad del lenguaje, la autonomía estética y el reconocimiento de los grandes tópicos de la mitología occidental.

En lo que respecta a la segunda fase, esta revisa las limitaciones de las tradiciones continentales y nacionales, y opta por la definición del compromiso social y una visión religiosa de lo humano que inicia su concepción de poesía como redención, evangelio y síntesis cognitiva. Y, finalmente, tenemos una fase de tránsito, que recupera los elementos míticos grecolatinos y religiosos judeocristianos para modelarlos bajo una ética que prepara el camino a la mitologización de la caída y redención humanas de sus poemarios. Pese a corresponder a una etapa inexplorada y adolecer de un lenguaje mimético, los primeros poemas de Rojas Herazo soportan los fundamentos de una poética de la escritura que le permitirá distanciarse tanto de la tradición humanista clásica como retomar la línea americanista de Martí, Sarmiento, Rodó y Vasconcelos. O lo que es lo mismo, el programa que Rodó encontraba anunciado en el romanticismo latinoamericano (Carrilla, 1968, p. 545).

Años más tarde, la visión americanista y la función religiosa de su poesía, en tanto evangelio secular, serán entendidas por Rojas Herazo, por un lado, como acumulación y unión totalizante de epistemes, y por otro, como síntesis de lo "clásico" y lo "nuevo". Propondrá para entonces lo americano en tanto fuente que ha de producir el "acento definitivo de lo humano" (Rojas Herazo, 2003a, p. 499). Tal postulado implica una visión del arte como unidad, que procede, a su vez, de una conciencia unitaria del "sujeto americano" en cuanto heredero de la civilización occidental. En este sentido, su occidentalismo estético simplificará crisis y rupturas en beneficio de un programa ideológico mayor: la dimensión redentora de la poesía. Si bien es cierto que en 1955 Rojas Herazo considera por algunos momentos que las búsquedas americanistas pueden crear una romantización hemisferial, un "canto de sirena" o una "fantasmagoría” continental (Rojas Herazo, 2003b, p. 471.), la defensa del proyecto continuará en la década del 50 como validación de los fundamentos de su concepción mito-poética de la poesía.

\section{Referencias bibliográficas}

América Española. (1940). América española (agosto), p. 288.

Arango, G. (1995). Un ramo de nomeolvides. Cartagena: El Universal. 
Carrilla, E. (1968). Raíces del americanismo literario. Thesaurus 23 (3), pp. 536-546.

El Universal (1949). Poemas de Rojas Herazo. El Universal (1 de octubre), p. 4.

E1 Universal (1950). Un saludo a Rojas Herazo. El Universal (7 de febrero), p. 4.

El Universal (1951). Saludo a Rojas Herazo. El Universal (24 de octubre), s. p.

Fuenmayor, A. (1947). Arcilla de Rojas Herazo. El Heraldo (13 de diciembre), p. 12.

García Márquez, G. (2005). Textos costeños. Obra periodística 1 (1948-1952). Bogotá: Random House Mondadori.

García Nossa, A. (1940). De Valencia a Carranza. El Tiempo (24 de agosto), pp. 1-2.

Ortemberg, P. (2017). Panamericanismo, hispanoamericanismo y nacionalismo en los festejos identitarios de América Latina, 1880-1920. Perfomances y encrucijadas diplomáticos e intelectuales. Anuario IEHS XXXII (1), pp. 99-110.

Rojas Herazo, H. (1940). Canción de la niña imposeída. El Heraldo (9 de julio), s. p.

Rojas Herazo, H. (1947a). Job en el Hombre. El Heraldo (13 de diciembre), p. 12.

Rojas Herazo, H. (1947b). Palabras elegiacas a un soldado. El Heraldo (13 de diciembre), p. 12.

Rojas Herazo, H. (1948a). Un poeta nicaragüense. El Universal (27 de junio), p. 4.

Rojas Herazo, H. (1948b). El hombre de América debe saber cual [sic] destino merece y cual desea para sacar en conclucion [sic] cual necesita. El Universal (30 de junio), pp. 1, 8.

Rojas Herazo, H. (1948c). Invocación vital para mi hermano el hombre. El Universal (2 de julio), p. 7.

Rojas Herazo, H. (1948d). Invitación al hombre universal. El Universal (2 de julio), p. 7.

Rojas Herazo, H. (1949). El habitante destruido. Sábado (1 de octubre), p. 6

Rojas Herazo, H. (2003a). Vigilia de las lámparas. Obra periodística, 1940-1970. Medellín: Eafit.

Rojas Herazo, H. (2003b). La magnitud de la of renda. Obra periodística, 1940-1970. Medellín: Eafit.

Sanclemente, Á. (1948). Examen de la literatura en 1947. Sábado (10 de enero), pp. 3, 14.

Urrego Ardila, M. A. (2002). Intelectuales, Estado y Nación en Colombia. De la guerra de los Mil Días a la constitución de 1991. Recuperado de http://books.openedition.org/sdh/270

Vinyes, R. (1947). El hombre y su voz. El Heraldo (13 de diciembre), p. 12.

Zabala, C. M. (1948). Sección “Antología”. El Universal (18 de septiembre), p. 7.

\section{Archivos}

Archivo Biblioteca Bartolomé Calvo, Cartagena.

Archivo Biblioteca Nacional de Colombia, Bogotá.

Archivo El Heraldo, Barranquilla.

Archivo El Universal, Cartagena.

Archivo Histórico de Cartagena. 